\title{
Reattachment Theory
}


A Camera Obscura book 


\section{Reattachment Theory QUeER CINEMA OF REMARRIAGE Lee Wallace}


(C) 2020 Duke University Press

All rights reserved

Printed in the United States of America on acid-free paper $\infty$

Designed by Amy Ruth Buchanan

Typeset in Whitman by Westchester Publishing Services.

Library of Congress Cataloging-in-Publication Data

Names: Wallace, Lee, [date] author.

Title: Reattachment theory : queer cinema of remarriage /

Lee Wallace.

Description: Durham : Duke University Press, 2020.|

Series: A camera obscura book | Includes bibliographical

references and index.

Identifiers: LCCN 2019034742 (print)

LCCN 2019034743 (ebook)

ISBN 9781478006817 (hardcover)

ISBN 9781478008101 (paperback)

ISBN 9781478009139 (ebook)

Subjects: LCSH: Same-sex marriage. | Marriage. | Lesbianism in motion pictures. | Homosexuality in motion pictures.

Classification: LCC HQ1O33 .w35 2020 (print)|

LCC HQ1O33 (ebook) | DDC 306.84/8-dc23

LC record available at https://lccn.loc.gov/2019034742

LC ebook record available at https://lccn.loc.gov/2019034743

Cover art: A Single Man, Tom Ford, 2009. Courtesy of Photofest. 
For the Stanleys of this world 
This page intentionally left blank 


\section{There is no marriage without remarriage. -Stanley Cavell, Cities of Words}


This page intentionally left blank 